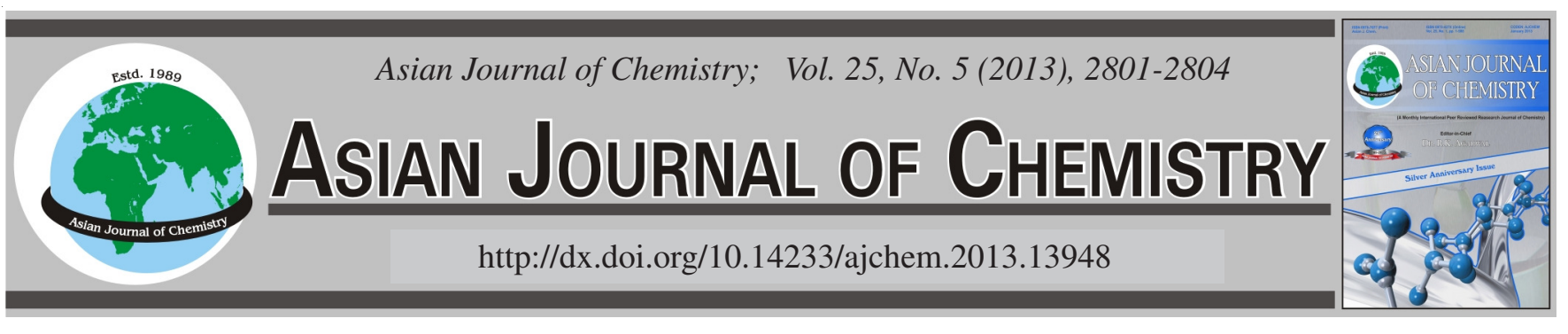

\title{
Production of Multiple Freshwater by Reverse Osmosis Seawater Desalination
}

\author{
YANYUE Lu ${ }^{1, *}$, ANPING LiaO ${ }^{1}$ and YANGDONG $\mathrm{Hu}^{2}$
}

${ }^{1}$ Key Laboratory of Chemical and Biological Transforming Process, Guangxi Key Laboratory of Chemistry and Engineering of Forest Products, College of Chemistry and Chemical Engineering, Guangxi University for Nationalities, Nanning 530006, P.R. China ${ }^{2}$ College of Chemistry and Chemical Engineering, Ocean University of China, Qingdao 266003, P.R. China

*Corresponding author: Tel: +86 771 326558; E-mail: luyanyue@163.com

\begin{abstract}
An optimization method based on process synthesis has been presented and applied to design a reverse osmosis system. Multiple freshwater can be produced by the seawater desalination system using reverse osmosis membrane module. A simplified superstructure that contains all the feasible design for this desalination problem has been presented firstly. Then, membrane separation units employing the spiral wound reverse osmosis elements were described by using a pressure vessel model, which takes into account the pressure drop and concentration changes in the membrane channel. The optimum design problem can be formulated as a mixed-integer non-linear programming problem, which minimizes the total annualized cost of the reverse osmosis system. The effectiveness of this design methodology has been demonstrated by solving a desalination case.
\end{abstract}

Key Words: Reverse osmosis, Seawater desalination, Optimum design, Structure, Module model.

\section{INTRODUCTION}

The freshwater production by seawater desalination is the main approach to solve the water shortage. In last few years, the reverse osmosis ( $\mathrm{RO}$ ) process of seawater desalination has gained much popularity. The interest in reverse osmosis is due to its low energy, high product recovery and quality. Another advantage of the reverse osmosis process is that it is able to meet varying feed water concentration and varying production water quantity and quality requirement through change system construction and operation condition. All this advantages have made the design of reverse osmosis process more flexible ${ }^{1-3}$.

Several research efforts have been directed to the design and optimization of reverse osmosis system ${ }^{4,5}$. El-Halwagi ${ }^{6}$ investigated the setup of reverse osmosis networks which involve multiple feed streams for waste reduction. Zhu et al. ${ }^{7}$ used El-Halwagi's representation and included a factor for flux decline over time. Voros et al. ${ }^{8}$ simplified the El-Halwagi's representation by reducing the distribution boxes to junctions. Van der Meer et al. ${ }^{910}$ have developed a simplified mathematical model to optimize the performance of NF and reverse osmosis membrane filtration plants. The study showed that the productivity of nanofiltration plants can be significantly improved by installing a reduced number of membrane elements serially in pressure vessels (PV) and changing system configuration. Malek et al. ${ }^{11}$ provided the realistic economic model that relates the various operational and capital cost elements to the design variable values.

In this work, reverse osmosis-based desalination process is considered for the production of multiple freshwater from seawater. A systematic methodology for the optimal design of reverse osmosis desalination system that supplies the various product water of different concentration is presented. The adoption of this approach can provide an economically attractive desalination scheme. It can lead to significant capital cost and energy saving and provide income from the multiple product water sales.

Reverse osmosis network representation: For the reverse osmosis system of seawater desalination with multipleproduct requirement, the design objective is to identify the most cost effective reverse osmosis network configuration, the optimal streams distribution and operating conditions and the optimal arrangement of the membrane elements. Fig. 1 represents a potential process configuration for this desalination problem.

It is necessary to develop a structural representation that contains all the feasible designs for the problem of synthesizing reverse osmosis network. El-Halwagi ${ }^{6}$ and Voros et al. ${ }^{8}$, have presented a network representation based on the state space approach. Here we adopt and properly modify the approach and presented a simplified superstructure that incorporates all the feasible process flow for the reverse osmosis system of 


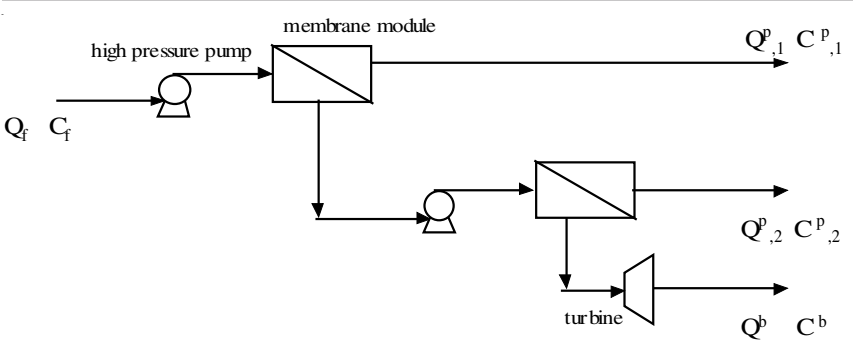

Fig. 1. Reverse osmosis process configuration with multiple-product requirement

seawater desalination with multiple-product requirement. As shown in Fig. 2, a reverse osmosis network consists of $\mathrm{N}_{\mathrm{ps}}$ pressurization stages and $\mathrm{N}_{\mathrm{RO}}$ reverse osmosis stages. In this configuration, there are three sets of stream nodes employed: $\mathrm{N}_{\mathrm{ps}}$ mixing junctions, $\mathrm{N}_{\mathrm{RO}}$ reverse osmosis junctions, $\mathrm{N}_{\mathrm{p}}$ outlet junctions of product streams. The junction of $\mathrm{N}_{\mathrm{ps}}+1$ indicated the brine stream leaving the network. It is assumed that seawater only enter the reverse osmosis system from stage 1. Each of the $\mathrm{N}_{\mathrm{ps}}$ mixing junctions indicates that the brine and the permeate streams leaving all reverse osmosis stages can mix at the node. The mixing streams pressurized by high pressure (HP) pump or not are connected to the corresponding reverse osmosis stages. The reverse osmosis stages consist of multiple parallel reverse osmosis pressure vessels operating at the same conditions.

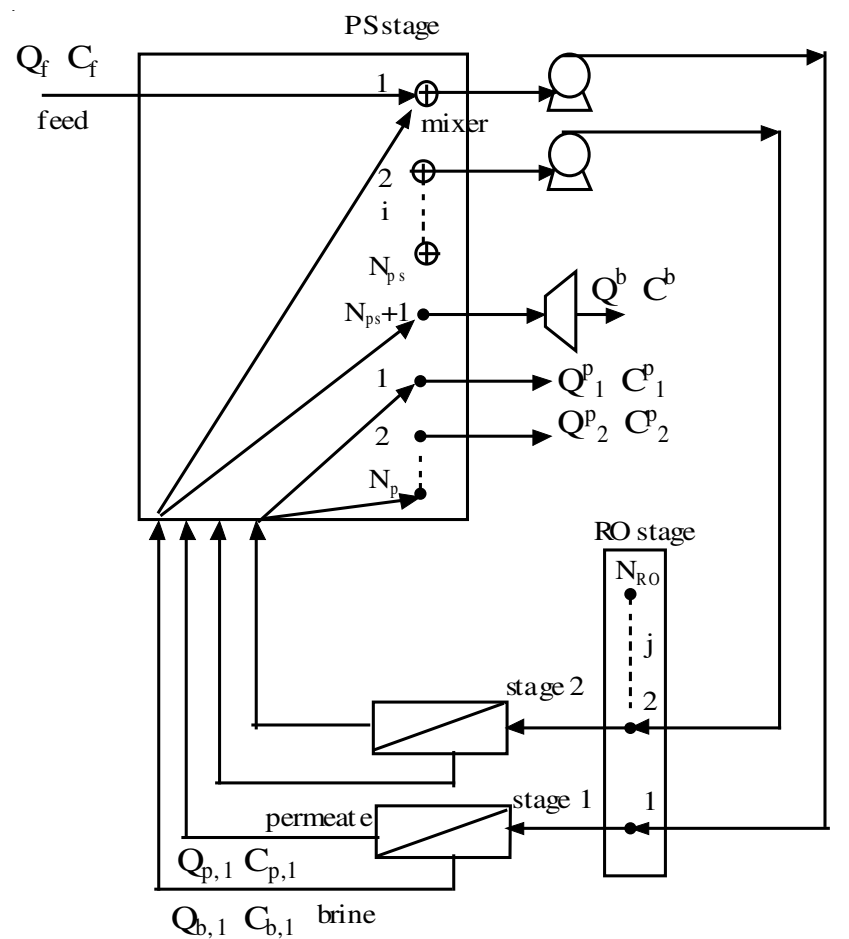

Fig. 2. Representation of the reverse osmosis network via the superstructure

Mathematical formulation: The complete mathematical model that describes the superstructure is presented as follow by means of the appropriate relationships between the variables (material and energy balance equations, technical and operational constraints).

$$
\mathrm{Q}_{\mathrm{ps}, 1} \times \mathrm{C}_{\mathrm{ps}, 1}=\mathrm{Q}_{\mathrm{f}} \times \mathrm{C}_{\mathrm{f}}+\sum_{\mathrm{j}=1}^{\mathrm{N}_{\mathrm{RO}}} \mathrm{Q}_{\mathrm{b}, \mathrm{j}} \times \mathrm{x}_{\mathrm{b}, 1, \mathrm{j}} \times \mathrm{C}_{\mathrm{b}, \mathrm{j}}
$$

$$
\begin{gathered}
+\sum_{j=1}^{N_{R O}} Q_{p, j} \times x_{p, 1, j} \times C_{p, j} \\
Q_{p s, i} \times C_{p s, i}=\sum_{j=1}^{N_{R O}} Q_{b, j} \times x_{b, i, j} \times C_{b, j}+\sum_{j=1}^{N_{R O}} Q_{p, j} \times x_{p, i, j} \times C_{p, j} \\
Q_{p s, N_{p s}+1} \times C_{p s, N_{p s}+1}=\sum_{j=1}^{N_{R O}} Q_{b, j} \times x_{b, N_{p s}+1, j} \times C_{b, j} \\
\sum_{i=1}^{N_{p s}+1} x_{b, i, j}=1 j=1,2, \ldots, N_{R O} \\
\sum_{i=1}^{N_{p s}+N_{p}} x_{p, i, j}=1 j=1,2, \ldots, N_{R O}
\end{gathered}
$$

where $\mathrm{Q}_{\mathrm{ps}, \mathrm{i}}, \mathrm{C}_{\mathrm{ps}, \mathrm{i}}$ denote the flow rate and concentration of the ith pressurization stage, respectively. $\mathrm{Q}_{\mathrm{b}, \mathrm{j}}, \mathrm{C}_{\mathrm{b}, \mathrm{j}}$ denote the brine flow rate and concentration of the $\mathrm{jth}$ reverse osmosis stage, $\mathrm{Q}_{\mathrm{p}, \mathrm{j}}, \mathrm{C}_{\mathrm{p}, \mathrm{j}}$ denote the permeate flow rate and concentration of the $\mathrm{jth}$ reverse osmosis stage, respectively. $\mathrm{x}_{\mathrm{b}, \mathrm{i}, \mathrm{j}}, \mathrm{x}_{\mathrm{p}, \mathrm{i}, \mathrm{j}}$ indicate the stream split ratios of the brine and permeate, respectively. The values determine the flow rates of brine and permeate leaving the jth reverse osmosis stage and being linked to the ith pressurization stage.

All the streams connected to the ith pressurization stage firstly mix in the mixer. The outlet pressure from the mixer is the smallest feed pressure. The stream split ratios and the logical expression of stream mixing are employed in this paper, these techniques reduced the number of binary variable and the solving space, therefore the mathematical model may be easily handled.

The mathematical model that predict the performance of reverse osmosis process is mainly based on two parameters: the water permeability, A and the solute transport parameter, B. The values for these two parameters are usually specified by membrane manufactures. According to the model, the pure water flux, $\mathrm{J}_{\mathrm{w}}\left(\mathrm{kg} / \mathrm{m}^{2} \mathrm{~s}\right)$ and the salt flux, $\mathrm{J}_{\mathrm{s}}\left(\mathrm{kg} / \mathrm{m}^{2} \mathrm{~s}\right)$, are given as follow:

$$
\begin{gathered}
\mathrm{J}_{\mathrm{w}}=\mathrm{A}\left[\left(\mathrm{P}_{\mathrm{f}}-\mathrm{P}_{\mathrm{p}}-\frac{\Delta \mathrm{P}_{\mathrm{f}}}{2}\right)-\left(\pi_{\mathrm{w}}-\pi_{\mathrm{p}}\right)\right] \times 10^{6} \\
\mathrm{~J}_{\mathrm{s}}=\mathrm{B}\left(\mathrm{C}_{\mathrm{w}}-\mathrm{C}_{\mathrm{p}}\right)
\end{gathered}
$$

The arrays of pressure vessels (PV) with 1 up to 8 membrane elements per pressure vessels consist of a reverse osmosis stage. In this paper, the optimal pressure vessels structure has been researched. Four different types of spiral wound FilmTec reverse osmosis membrane elements have been considered. According to its performance characteristics and the design requirements, the optimum selection of types of the membrane element employed in each pressure vessels can be determined.

The overall material balances for the reverse osmosis network and a set of product quantity and quality constraints concerning the minimum desirable product flow rate and the maximum allowable product concentration are presented as follow: 


$$
\begin{gathered}
Q_{f} \times C_{f}=Q^{b} \times C^{b}+\sum_{r=1}^{N_{p}} Q_{r}^{p} \times C_{r}^{p} \\
Q_{r}^{p} \times C_{r}^{p}=\sum_{j=1}^{N_{R O}} Q_{p, j} \times x_{p, r, j} \times C_{p, j} r=1,2, \ldots, N_{p} \\
Q_{r}^{p} \geq Q_{r, \min }^{p} r=1,2, \ldots, N p \\
C_{r}^{p} \leq C_{r, \max }^{p} r=1,2, \ldots, N_{p}
\end{gathered}
$$

where $\mathrm{Q}^{\mathrm{b}}, \mathrm{C}^{\mathrm{b}}$ are the flow rate and concentration of the brine leaving the reverse osmosis network, respectively. $\mathrm{Q}_{\mathrm{r}}^{\mathrm{p}}, \mathrm{C}_{\mathrm{r}}^{\mathrm{p}}$ are the flow rate and concentration of the rth product water required, respectively. $\mathrm{x}_{\mathrm{p}, \mathrm{rj}}$ are the outlet stream split ratios. $\mathrm{Q}_{\mathrm{r} \text {,min }}^{\mathrm{p}}$ refers to the minimum desirable flow rate of the rth product required, $\mathrm{C}_{\mathrm{r}, \max }^{\mathrm{p}}$ refers to the maximum allowable concentration of the rth product required.

Solution methodology: The optimization design problem is formulated as a mixed-integer nonlinear programming (MINLP) for minimizing the total annualized cost subject to technical and flexibility constraints. The total annualized cost (TAC) of the system consists of two terms: annual operating cost (OC) and annualized capital cost (CC). The objective function is presented as follow:

$$
\begin{aligned}
\mathrm{TAC}=\left(\mathrm{CC}_{\mathrm{in}}+\mathrm{CC}_{\mathrm{hpp}}+\mathrm{CC}_{\mathrm{Tb}}+\mathrm{C}_{\mathrm{m}}\right) \times 1.411 \times 0.08 \\
+\mathrm{OC}_{\mathrm{in}}+\mathrm{OC}_{\mathrm{hpp}}-\mathrm{OC}_{\mathrm{Tb}}+\mathrm{OC}_{\mathrm{m}}
\end{aligned}
$$

where $\mathrm{CC}_{\mathrm{in}}, \mathrm{CC}_{\mathrm{hpp}}$ and $\mathrm{CC}_{\mathrm{Tb}}$ are the capital cost of the seawater intake pump, the high pressure pump and the turbine, respectively. $\mathrm{OC}_{\mathrm{in}}, \mathrm{OC}_{\mathrm{hpp}}$ and $\mathrm{OC}_{\mathrm{Tb}}$ are the energy cost necessary for these pumps and the saving cost generated by turbine. Their functions refer to the papers ${ }^{1,7,11} \cdot \mathrm{C}_{\mathrm{m}}$ denotes the total membrane module cost. 1.411 is the coefficient that used to calculate the practical investment. 0.08 is the capital charge rate. The MINLP can be solved using the software GAMS.

Case study: The proposed methodology for reverse osmosis system optimization design has been applied to deals with the desalination of seawater. In this case, there are three kinds of product water required, which subject to different permeate quantity and quality constraints. The minimum desirable product flow rate for these outlets are 200, 100 and $50 \mathrm{~m}^{3} / \mathrm{h}$, while the corresponding maximum allowed salt concentration are 100, 300 and 500 ppm, respectively. Four different types of FilmTec reverse osmosis membrane elements from DOW have been included in the design studies of the current work. They are the low energy, high productivity element SW30XLE-400, the high rejection, high productivity element SW30HR-380, the high rejection, fouling resistant element SW30HR-320 and the high productivity, high rejection brackish reverse osmosis element BW30-400. The necessary input data for this case study are summarized in Table- $1^{7,11}$.

The results of the reverse osmosis system optimization design were presented in Table-2. The two-stage reverse osmosis configuration with brine re-processing was employed in design (Fig. 3). This scheme supplies three kinds of product water. The first product water come from the permeate of stage $1\left(\mathrm{x}_{\mathrm{p}, 5,1}=0.828\right)$ which concentration is lower, while the third

\begin{tabular}{|c|c|}
\hline \multicolumn{2}{|c|}{$\begin{array}{c}\text { TABLE-2 } \\
\text { DESIGN AND OPTIMIZATION } \\
\text { RESULTS FOR THE STUDY CASE }\end{array}$} \\
\hline Process flow & $\begin{array}{c}\text { Two-stage RO } \\
\text { system, show as } \\
\text { Fig. } 3\end{array}$ \\
\hline Seawater feed flow, $Q_{\mathrm{f}}\left(\mathrm{m}^{3} / \mathrm{h}\right)$ & 588 \\
\hline Flow rate of the first product water, $\mathrm{Q}^{\mathrm{p}}\left(\mathrm{m}^{3} / \mathrm{h}\right)$ & 200 \\
\hline $\begin{array}{l}\text { Salt concentration of the first product water, } \mathrm{C}^{\mathrm{p}}{ }_{1} \\
(\mathrm{ppm})\end{array}$ & 100 \\
\hline Flow rate of the second product water, $\mathrm{Q}_{2}^{\mathrm{p}}\left(\mathrm{m}^{3} / \mathrm{h}\right)$ & 100 \\
\hline $\begin{array}{l}\text { Salt concentration of the second product water, } \mathrm{C}_{2}^{\mathrm{p}} \\
(\mathrm{ppm})\end{array}$ & 300 \\
\hline Flow rate of the third product water, $\mathrm{Q}_{3}^{\mathrm{p}}\left(\mathrm{m}^{3} / \mathrm{h}\right)$ & 50 \\
\hline $\begin{array}{l}\text { Salt concentration of the third product water, } \mathrm{C}_{3}^{\mathrm{p}} \\
(\mathrm{ppm})\end{array}$ & 430 \\
\hline Membrane type in stage 1 & SW30HR-320 \\
\hline Number of elements per PV in stage 1 & 3 \\
\hline Number of PV in stage 1 & 81 \\
\hline Operating pressure in stage $1, \mathrm{P}_{1}(\mathrm{Mpa})$ & 8.2 \\
\hline Membrane type in stage 2 & SW30XLE-400 \\
\hline Number of elements per PV in stage 2 & 4 \\
\hline Number of PV in stage 2 & 53 \\
\hline Operating pressure in stage $2, \mathrm{P}_{2}(\mathrm{Mpa})$ & 8.3 \\
\hline The overall system recovery & $59 \%$ \\
\hline The total annualized cost, $(\$)$ & $1,397,600$ \\
\hline
\end{tabular}
product water come from the permeate of stage $2\left(x_{\mathrm{p}, 7,2}=0.46\right)$. The second product water consist of partial permeate coming from stage $1\left(x_{p, 6,1}=0.172\right)$ and stage $2\left(x_{p, 6,2}=0.54\right)$. The total annualized cost of the system is $\$ 1,397,600$ per year.

\begin{tabular}{lc}
\multicolumn{2}{c}{ TABLE-1 } \\
PARAMETERS FOR CALCULATION \\
\hline Feed concentration of seawater $(\mathrm{ppm})$ & 35000 \\
Feed water average temperature $\left({ }^{\circ} \mathrm{C}\right)$ & 25 \\
Average brine density, $\rho\left(\mathrm{kg} / \mathrm{m}^{3}\right)$ & 1020 \\
The average brine viscosity, $\mu(\mathrm{kg} / \mathrm{m} \mathrm{s})$ & $1.09 \times 10^{-3}$ \\
Average diffusion coefficient, $\mathrm{D}_{\mathrm{s}}\left(\mathrm{m}^{2} / \mathrm{s}\right)$ & $1.35 \times 10^{-9}$ \\
High pressure pump efficiency, $\eta_{\mathrm{hpp}}$ & $75 \%$ \\
Turbine efficiency, $\eta_{\mathrm{Tb}}$ & $80 \%$ \\
Electric motor efficiency, $\eta_{\text {motor }}$ & $98 \%$ \\
The cost of electricity, $\mathrm{C}_{\mathrm{e}}, \$(\mathrm{kwh})^{-1}$ & 0.08 \\
The pressure vessel cost, $(\mathrm{estimation}) \$$ & 1000 \\
\hline
\end{tabular}

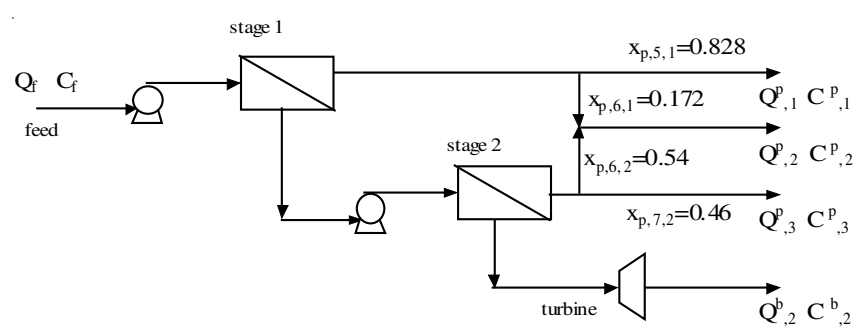

Fig. 3. Optimal reverse osmosis configuration with multiple-product outlets

\section{Conclusion}

A process synthesis method has been applied to the optimal design of reverse osmosis system with multiple product water outlets for seawater desalination. The representation of reverse osmosis networks via the superstructure incorporates all feasible arrangements for this desalination problem. Then, this superstructure was used to develop the general mathematical model by means of the appropriate relationships between the variables. Finally, the design task has been formulated as an MINLP which minimizes the total annualized cost of the reverse osmosis system. The solution of the problem includes the 
optimal system structure and operating conditions, the optimal streams distribution and the optimal output of the system. The design method could also be used for the optimal selection of type and number of membrane elements in each stage and in each pressure vessel.

\section{ACKNOWLEDGEMENTS}

Financial support from the Natural Science Foundation of Guangxi (No. 2012GXNSFAA053025), the Education Department of Guangxi, China (200812MS084) and Guangxi Higher Education Institutes Talent Highland Innovation Team Scheme (GJR201147-12) are gratefully acknowledged.

\section{REFERENCES}

1. A. Villafafila and I.M. Mujtaba, Desalination, 155, 1 (2003).

2. M. Wilf and C. Bartels, Desalination, 173, 1 (2005).
3. Membrane Technical Information, http://www.dow.com/liquidseps/ service/lm techinfo.htm.

4. Y.-Y. Lu, Y.-D. Hu, D.-M. Xu and L.-Y. Wu, J. Membr. Sci., 282, 7 (2006).

5. Y.-Y. Lu, Y.-D. Hu, X.-L. Zhang, L.-Y. Wu and Q.-Z. Liu, J. Membr. Sci., 287, 219 (2007).

6. M.M. El-Halwagi, AICHE J., 38, 1185 (1992).

7. M.J. Zhu, M.M. El-Halwagi and M. Al-Ahmad, J. Membr. Sci., 129, 161 (1997).

8. N.G. Voros, Z.B. Maroulis and D. Marinos-Kouris, J. Membr. Sci., 127, 47 (1997).

9. W.G.J. Van der Meer, M. Riemersma and J.C. van Dijk, Desalination, 119, 57 (1998)

10. L.P. Wessels, W.G.J. Van der Meer, W.C. Van Paassen and G. Vos, Desalination, 119, 341 (1998).

11. A. Malek, M.N.A. Hawlader and J.C. Ho, Desalination, 105, 245 (1996). 